\title{
Uromodulin Storage Diseases: Clinical Aspects and Mechanisms
}

\author{
Francesco Scolari, MD, Gianluca Caridi, PhD, Luca Rampoldi, PhD, Regina Tardanico, MD, \\ Claudia Izzi, MD, Doroti Pirulli, PhD, Antonio Amoroso, MD, Giorgio Casari, PhD, and \\ Gian Marco Ghiggeri, MD
}

\begin{abstract}
- The recent discovery of mutations in the uromodulin gene (UMOD) in patients with medullary cystic kidney disease type 2 (MCKD2), familial juvenile hyperuricemic nephropathy (FJHN), and glomerulocystic kidney disease (GCKD) provides the opportunity for a revision of pathogenic aspects and puts forth the basis for a renewed classification. This review focuses on clinical, pathological, and cell biology advances in UMOD-related pathological states, including a review of the associated clinical conditions described to date in the literature. Overall, 31 UMOD mutations associated with MCKD2 and FJHN (205 patients) and 1 mutation associated with GCKD (3 patients) have been described, with a cluster at exons 4 and 5 . Most are missense mutations causing a cysteine change in uromodulin sequence. No differences in clinical symptoms between carriers of cysteine versus polar residue changes have been observed; clinical phenotypes invariably are linked to classic MCKD2/FJHN. A common motif among all reports is that many overlapping symptoms between MCKD2 and FJHN are present, and a separation between these 2 entities seems unwarranted or redundant. Cell experiments with mutant variants indicated a delay in intracellular maturation and export dynamics, with consequent uromodulin storage within the endoplasmic reticulum (ER). Patchy uromodulin deposits in tubule cells were found by means of immunohistochemistry, and electron microscopy showed dense fibrillar material in the ER. Mass spectrometry showed only unmodified uromodulin in urine of patients with UMOD mutations. Lack of uromodulin function(s) is associated with impairments in tubular function, particularly the urine-concentrating process, determining water depletion and hyperuricemia. Intracellular uromodulin trapping within the ER probably has a major role in determining tubulointerstitial fibrosis and renal failure. We propose the definition of uromodulin storage diseases for conditions with proven UMOD mutations. Am J Kidney Dis 44:987-999.
\end{abstract}

(c) 2004 by the National Kidney Foundation, Inc.

INDEX WORDS: Uromodulin; Tamm-Horsfall protein; medullary cystic kidney disease (MCKD); familial juvenile hyperuricemic nephropathy (FJHN); glomerulocystic kidney disease (GCKD).

$\mathbf{R}$ ENAL CYSTIC DISEASES are the major group of inherited renal conditions in humans, representing a leading cause of end-stage renal disease in the world. Polycystic kidney disease (PKD), in both the dominant and recessive variants, accounts for most of the relevant clinical conditions. However, nephronophthisis (NPH), medullary cystic kidney disease (MCKD), and dominant glomerulocystic kidney disease (GCKD) together still cause a relevant clinical impact, mostly in children. ${ }^{1}$

Recent advances in the field of molecular genetics provide the opportunity for revision of the pathogenic aspects of renal cystic diseases and put forth the basis for a renewed classification. Starting from 1997, causative mutations in 4 genes for NPH (NPHP1, NPHP2, NPHP3, and NPHP4) have been identified, ${ }^{2-5}$ and based on functional genomics, some links between the NPH family and PKD genes were described.

In parallel to these developments, seminal work by Hart et $\mathrm{al}^{6}$ led to the discovery of mutations in $U M O D$, the gene encoding uromodulin, in large pedigrees with MCKD type 2 (MCKD2; Mendelian Inheritance in Man 603860) and familial juvenile hyperuricemic nephropathy
(FJHN; Mendelian Inheritance in Man 162000). This finding later was confirmed by other groups $^{7-14}$ and recently was extended to autosomal dominant GCKD. ${ }^{10}$ Uromodulin (also known as Tamm-Horsfall protein) was found to be accumulating in patch aggregates in all these conditions, suggesting a common pathogenesis. ${ }^{9,10}$ Thus, once again, on the basis of the molecular and functional similarities, the mentioned condi-

From the Laboratorio di Fisiopatologia dell'Uremia, Istituto Giannina Gaslini, Genova; Divisione di Nefrologia and Sezione di Patologia, Spedali Civili, Brescia; Cattedra di Genetica, Università di Trieste; Human Molecular Genetics Unit and Dulbecco Telethon Institute, Dibit, Hospital San Raffaele, Milano, Italy.

Received April 5, 2004; accepted in revised form August 16, 2004

Supported in part by grant no. GP0400Y02 and grant no. TCP03018 (L.R.) from Telethon-Italy; and the Kidney Foundation for Studies in Children. L.R. is an Assistant Telethon Scientist.

Address reprint requests to Gian Marco Ghiggeri, MD, Laboratorio di Fisiopatologia dell'Uremia, IRCCS Gaslini,

Genova, Italy.E-mail: labnefro@ospedale-gaslini.ge.it

(C) 2004 by the National Kidney Foundation, Inc.

0272-6386/04/4406-0004\$30.00/0

doi:10.1053/j.ajkd.2004.08.021 
tions were tentatively grouped under the definition of $U M O D$-related diseases.

Therefore, 2 separate lines of evidence support the concept that the NPH and MCKD, although previously considered the recessive and dominant counterparts of the same disease complex, should be differentiated clearly and classified more simply according to the molecular advances deriving from functional genomics.

This review focuses on the clinical, pathological, molecular, and cell biology advances in $U M O D$-related pathological states, including a detailed review of clinical conditions in which $U M O D$ mutations have been reported. Data for an animal model with $U M O D$ genetic ablation also are discussed. Together, these findings support the need for separation of diseases related to $U M O D$ mutations from other cystic kidney diseases, and we propose, on the basis of pathological and experimental results, the definition of uromodulin storage renal diseases.

\section{HISTORICAL BACKGROUND ON UROMODULIN STRUCTURE AND FUNCTIONS}

Uromodulin is a specific kidney protein produced in the thick ascending limb (TAL) of the loop of Henle. ${ }^{15,16} \mathrm{In}$ its mature form, it is mainly an extracellular protein anchored by glycosyl phosphatidylinositol functional group at the luminal face of tubular epithelia. Uromodulin is excreted, representing the most abundant protein in urine of healthy individuals. Based on the typical gelling properties and localization at the TAL, where permeability to water typically is low, it was historically hypothesized that uromodulin's major function is to maintain water impermeability at this site. ${ }^{17}$ Successive studies investigated many other putative functions of the protein that was later considered a primary defense against bacteria (discussed next). The structural features of uromodulin have been reviewed extensively by Serafini-Cessi et $\mathrm{al}^{18}$ in a recent issue of this journal. However, a few structural outlines could make understanding easier of fine mechanisms involved in pathogenesis of $U M O D$ related diseases. Uromodulin is a very highly conserved protein with a high degree of sequence similarity (77\% to $83 \%$ identities) with rat, mouse, dog, and cow homologues. ${ }^{19-25}$ The protein includes a high content of cysteine residues (48 of 640 amino acids; 7.5\%), suggesting a complex conformational architecture. Uromodulin has an N-terminal 24-amino acid signal peptide (absent in the mature protein), ${ }^{19} 4$ calcium-binding epidermal growth factor (cbEGF)-like domains, a zona pellucida-like domain from amino acid 336 to 585 , and a glycosyl phosphatidylinositol anchor attachment site at position 614 .

Despite significant speculation, the function of uromodulin remains unclear. Extensive research on uromodulin function supports the notion that the protein acts as a protective agent against bacteria in the urinary tract, competitively inhibiting adhesion of the type 1-fimbriated Escherichia coli to the urothelial surface. ${ }^{26-31}$ Uromodulin also has been considered the culprit of kidney pathological states that lead to the intraluminal formation of casts and/or stones, owing to its tendency to form a gel or aggregates. ${ }^{32-38}$

More recently, the clinical relevance of uromodulin has been emphasized by evidence that MCKD2 and FJHN arise from mutations of the UMOD gene. ${ }^{6}$

\section{UROMODULIN AND MEDULLARY CYSTIC KIDNEY DISEASE TYPE 2: THE UNEXPECTED LINK}

Traditionally, MCKD belongs to a heterogeneous group of inherited cystic tubulointerstitial nephritis, named NPH-MCKD complex. ${ }^{1}$ The 2 diseases share clinical features (polyuria, polydipsia, and anemia), macroscopic pathological characteristics (cysts primarily located at the corticomedullary border), and renal histological characteristics (tubular atrophy, interstitial fibrosis, and cell infiltration). NPH and MCKD also are characterized by 3 distinguishing features; mode of inheritance (recessive in NPH and dominant in MCKD), age of onset for end-stage renal disease (developing in childhood or adolescence in patients with NPH and adulthood in patients with MCKD), and extrarenal organ involvement (tapetoretinal degeneration and liver fibrosis in patients with NPH, gout and/or hyperuricemia in patients with MCKD).$^{39}$ The term NPH-MCKD complex has been proposed as a compromise appellation because of the inability to show a clear clinical and pathological distinction between them. ${ }^{36}$

Molecular genetics has definitely contributed to differentiate between NPH and MCKD. In the early 1990s, the first gene locus for NPH to 
human chromosome 2q12-q13 was mapped, and recently, 3 new genes were discovered. ${ }^{2-5}$ Interestingly, NPH genes colocalize with PKD genes to the primary cilium. ${ }^{4,5,40-44}$ Previously thought to be vestigial cellular organelles, primary cilia function as flow-sensitive mechanosensors. ${ }^{44}$ All products of mutated genes in NPH, ie, nephrocystin 1 , inversin, nephrocystin 3 , and nephroretinin, and the main proteins involved in autosomal dominant PKD, ie, polycystin-1 and polycystin-2, are cilia proteins. These data collectively suggest an unexpected link between the molecular mechanisms of pathogenesis in these cystic diseases. Conversely, 2 loci for dominant MCKD, MCKD1 and MCKD2, have been localized to chromosome 1q21 and 16p12, respectively. ${ }^{45,46}$ MCKD1 was mapped in a few kindreds from Cyprus that were characterized by diffuse renal cysts, hyperuricemia, and chronic renal failure. Probably, MCKD1 and MCKD2 cannot be readily differentiated on clinical grounds, and additional descriptions of families with MCKD1 are needed to show the clinical boundaries between the 2 genetic entities. The gene for FJHN, a phenotype (hyperuricemia, gout, progressive renal failure at an early age, and dominant inheritance) very similar to MCKD2, later was mapped to $16 \mathrm{p} 12$, in a region overlapping with the MCKD2 locus. ${ }^{47-49}$ Genetic heterogeneity of FJHN was shown in some families, resulting to be unlinked to the 16 p12 locus. ${ }^{9,47,50}$ That MCKD2 and FJHN loci mapped to the same critical region raised the question of whether MCKD2 and FJHN were allelic variants of the same disease entity. ${ }^{49}$ In 2002, Hart et $\mathrm{al}^{6}$ identified 4 novel UMOD gene mutations segregating with the disease phenotype in 3 families with FJHN and 1 family with MCKD2, providing evidence that MCKD2 and FJHN arise from mutation of the UMOD gene and are allelic disorders.

Furthermore, the existence of a yet to be identified third locus has been shown in a few reports of MCKD/FJHN families unlinked to both MCKD1 and MCKD2 loci. ${ }^{51,52}$

\section{HETEROGENEITY OF CLINICAL CONDITIONS ASSOCIATED WITH UROMODULIN GENE MUTATIONS}

After the seminal observation by Hart et al, ${ }^{6}$ a few confirmatory reports have been published. ${ }^{7-14}$ $U M O D$ mutations also were reported in a family with autosomal dominant GCKD. ${ }^{10}$ The presence of a genetic defect in $U M O D$ in MCKD2, FJHN, and GCKD (discussed next) showed that these 3 conditions are allelic. Overall, 8 families with MCKD2 and 24 families with FJHN have been described..$^{6-13}$ A common motif to all reports is that so many overlapping symptoms between MCKD2 and FJHN are present that separation between these 2 entities seems artful and probably clinically useless. For this reason, in the following sections devoted to the clinical description of UMOD-related diseases and genotype-phenotype correlations, MCKD2 and FJHN are discussed together.

\section{Medullary Cystic Kidney Disease 2 and Familial Juvenile Hyperuricemic Nephropathy}

The main clinicopathologic features, including the incidence of renal failure, hyperuricemia/ primary gout, and renal cysts, reported to date in patients carrying $U M O D$ mutations are listed in Table 1. In Table 1, which lists the original classification, the order of presentation of the affected family members follows the position of the nucleotide/amino acid change starting from the N-terminus. Overall, 33 families with 31 different $U M O D$ mutations, including 205 affected members, have been described. Fourteen mutations affect the cbEGF-like domains, with clusters in the 2 highly conserved exons 4 and 5; 17 additional mutations localize to a highly conserved protein region (residues 149 to 280) that has no sequence similarity to any reported domain. In the first case, ie, mutations in the cbEGFlike domains, most changes affect cysteine residues and are predicted to prevent a disulfide bond formation and therefore perturb the protein conformation. An additional mutation involves asparagine residue 128 at a predicted $\mathrm{Ca}^{++}$binding site, possibly loosing the calcium co-coordinating segment predicted to stabilize the tertiary structure. ${ }^{18}$ Eight amino acid changes mapping within the conserved region between residue 149 and 280 involve cysteine residues that probably contribute to protein folding, whereas 9 involve polar amino acid residues. Clinical features of the potentially different cohorts were similar: of 53 patients with mutations in 1 of the 4 predicted cbEGF domains, 41 patients $(77 \%)$ had chronic renal failure and 43 patients $(81 \%)$ also had primary hyperuricemia with gout, whereas only 
Table 1. Families With MCKD/FJHN and 32 Different UMOD Mutations Reported in the Literature to Date

\begin{tabular}{|c|c|c|c|c|c|c|c|c|c|c|c|}
\hline $\begin{array}{l}\text { Family } \\
\text { No. }\end{array}$ & Origin & $\begin{array}{c}\text { No. of } \\
\text { Affected } \\
\text { Individuals }\end{array}$ & $\begin{array}{c}\text { Chronic } \\
\text { Renal } \\
\text { Failure }\end{array}$ & Gout & Cysts & $\begin{array}{l}\text { Renal Histological } \\
\text { Characteristics }\end{array}$ & Classification & $\begin{array}{l}\text { Nucleotide } \\
\text { Change }\end{array}$ & Protein Change & $\begin{array}{l}U M O D \\
\text { Domain }\end{array}$ & Reference \\
\hline 1 & Japan & 2 & 2 & 2 & NA & NA & FJHN & $156 \mathrm{~T} \rightarrow \mathrm{G}$ & C52W & EGF II & 11 \\
\hline 2 & Belgium & 1 & 1 & - & 1 & NA & FJHN & $176 \mathrm{~A} \rightarrow \mathrm{C}$ & D59A & EGF II & 9 \\
\hline 3 & Austria & 8 & 6 & 8 & 3 & NA & FJHN & $230 \mathrm{G} \rightarrow \mathrm{A}$ & C77Y & EGF II & 8 \\
\hline 4 & NA & 6 & 6 & - & 3 & $3 / \mathrm{TIN}$ & MCKD2 & 278del12/ins9 & V93_G97delinsAASC & EGF II & 7 \\
\hline 5 & Not reported & 3 & 3 & 2 & 1 & * & MCKD2 & $307 \mathrm{G} \rightarrow \mathrm{T}$ & G103C & EGF II & 6 \\
\hline 6 & Belgium & 1 & 1 & 1 & 1 & NA & FJHN & $334 \mathrm{~T} \rightarrow \mathrm{C}$ & $\mathrm{C} 112 \mathrm{R}$ & EGF III & 9 \\
\hline \multirow[t]{2}{*}{7} & Italy & 2 & 2 & 2 & NA & NA & FJHN & $376 \mathrm{~T} \rightarrow \mathrm{C}$ & C126R & EGF III & 9 \\
\hline & Austria & 2 & NA & 2 & NA & NA & FJHN & $376 \mathrm{~T} \rightarrow \mathrm{C}$ & $\mathrm{C} 126 \mathrm{R}$ & EGF III & 8 \\
\hline 8 & Spain & NA & NA & NA & NA & NA & FJHN & $383 \mathrm{~A} \rightarrow \mathrm{G}$ & N128S & EGF III & 8 \\
\hline 9 & Japan & 7 & 6 & 7 & NA & NA & FJHN & $403 \mathrm{~T} \rightarrow \mathrm{A}$ & C135S & EGF III & 11 \\
\hline 10 & Not reported & 9 & 9 & 9 & NA & $1 / \mathrm{TIN}$ & FJHN & $443 \mathrm{G} \rightarrow \mathrm{A}$ & C148Y & EGF III & 6 \\
\hline 11 & Italy & 3 & 3 & 3 & - & NA & MCKD2 & $444 \mathrm{~T} \rightarrow \mathrm{C}$ & C148W & EGF III & 10 \\
\hline 12 & Italy & 17 & 11 & 11 & 4 & $1 / \mathrm{TIN}$ & MCKD2 & $449 \mathrm{G} \rightarrow \mathrm{A}$ & C150S & - & 10 \\
\hline 13 & France & 3 & 2 & 0 & 1 & NA & FJHN & $509 \mathrm{G} \rightarrow \mathrm{A}$ & C170Y & - & 9 \\
\hline 14 & Not reported & 38 & 28 & 34 & NA & 3/TIN & FJHN & 529_555del & H177_R185del & - & 6,13 \\
\hline 15 & Belgium & 11 & 5 & 6 & 3 & 3/TIN & FJHN & $553 \mathrm{C} \rightarrow \mathrm{A}$ & R185S & - & 9 \\
\hline 16 & France & 3 & 3 & 1 & NA & NA & FJHN & 563_661del & AA188-221del & - & 9 \\
\hline 17 & Japan & 3 & 3 & 2 & NA & NA & FJHN & $58 \overline{4} \mathrm{G} \rightarrow \mathrm{T}$ & C195F & - & 11 \\
\hline 18 & Japan & 4 & 4 & 4 & NA & NA & FJHN & $605 \mathrm{G} \rightarrow \mathrm{C}$ & W202S & - & 11 \\
\hline 19 & Morocco & 1 & 1 & 1 & - & NA & FJHN & $610 \mathrm{C} \rightarrow \mathrm{G}$ & R204G & - & 9 \\
\hline 20 & Belgium & 1 & 1 & 1 & - & NA & FJHN & $649 \mathrm{~T} \rightarrow \mathrm{G}$ & C217G & - & 9 \\
\hline 21 & Not reported & NA & NA & NA & NA & NA & FJHN & $649 \mathrm{~T} \rightarrow \mathrm{C}$ & $\mathrm{C} 217 \mathrm{R}$ & - & 6 \\
\hline 22 & France & 7 & 7 & 4 & 2 & $2 / T I N$ & FJHN & $665 \mathrm{G} \rightarrow \mathrm{C}$ & $\mathrm{R} 222 \mathrm{P}$ & - & 9 \\
\hline 23 & Not reported & 2 & 1 & 2 & 1 & $1 / \mathrm{TIN}$ & FJHN/MCKD2 & $665 \mathrm{G} \rightarrow \mathrm{A}$ & $\mathrm{C} 223 \mathrm{Y}$ & - & 12 \\
\hline 24 & France & 8 & 7 & 1 & 1 & $1 / \mathrm{TIN}$ & FJHN & $674 \mathrm{C} \rightarrow \mathrm{T}$ & T225M & - & 9 \\
\hline 25 & NA & 3 & 3 & 3 & 3 & 3/TIN & MCKD2 & $674 \mathrm{C} \rightarrow \mathrm{A}$ & T225L & - & 7 \\
\hline 26 & Japan & 20 & 17 & 15 & NA & NA & FJHN & $707 \mathrm{C} \rightarrow \mathrm{T}$ & P236L & - & 11 \\
\hline 27 & NA & 3 & 3 & 3 & 1 & $1 / \mathrm{TIN}$ & MCKD2 & $744 \mathrm{C} \rightarrow \mathrm{G}$ & C248W & - & 7 \\
\hline \multirow[t]{2}{*}{28} & Spain & 5 & 5 & 3 & NA & 3/TIN & FJHN & $784 \mathrm{G} \rightarrow \mathrm{A}$ & $\mathrm{C} 255 \mathrm{Y}$ & - & 8 \\
\hline & Spain & 23 & 10 & 9 & 3 & 3/TIN & FJHN/MCKD2 & $784 \mathrm{G} \rightarrow \mathrm{A}$ & C225Y(het/hom) & - & 14 \\
\hline 29 & France & 1 & 1 & 1 & NA & NA & FJHN & $844 \mathrm{~T} \rightarrow \mathrm{C}$ & C282R & EGF IV & 9 \\
\hline 30 & Spain & & & & & & FJHN & $898 \mathrm{~T} \rightarrow \mathrm{G}$ & C300G & EGF IV & 8 \\
\hline 31 & Italy & 3 & 3 & 3 & 3 & $\begin{array}{c}\text { 3/TIN glomerular } \\
\text { cysts }\end{array}$ & GCKD & $943 \mathrm{~T} \rightarrow \mathrm{C}$ & C315R & EGF IV & 10 \\
\hline 32 & Italy & 8 & 1 & 6 & 1 & 3/TIN & MCKD2 & $950 \mathrm{G} \rightarrow \mathrm{A}$ & C317Y & EGF IV & 10 \\
\hline
\end{tabular}

Abbreviations: NA, not available; TIN, tubulointerstitial nephritis; het, heterozygous state; hom, homozygous state.

${ }^{*}$ Renal histological characteristic reported for 3 other members of the family at necroscopy showing hyalin deposit in tubular cell and cyst dilatation in 1 individual. 
10 patients had renal cysts. However, in numerous cases, the presence of renal cysts had not been evaluated. By comparison, chronic renal failure was found in 111 of 152 patients (73\%) with mutation involving the 149 to 280 region, 100 patients $(66 \%)$ had hyperuricemia/gout, and 18 patients $(12 \%)$ had renal cysts. Therefore, most patients with $U M O D$ mutations have a combination of chronic renal failure and gout irrespective of type and site of mutation. Personalized data on specific clinical symptoms, such as urine osmolality and uric acid levels, are scanty and are reviewed in the sections on related mechanisms.

The clinical issue about the artful differentiation of MCKD2 and FJHN on the basis of medullary cysts in families classified as MCKD2 and hyperuricemia in FJHN warrants a comment. Overall, the diagnosis in families with mutations in the cbEGF domains was MCKD2 in 4 cases and FJHN in 11 cases, whereas 3 and 13 families with mutations in the 149 to 280 region were identified as MCKD2 and FJHN, respectively ${ }^{6-13}$ Moreover, we described a family composed of 17 affected individuals carrying the mutation C150S, in which half the patients presented a pure FJHN phenotype, characterized by isolated hyperuricemia and/or gout, and the remaining half had renal cysts at the corticomedullary junction. ${ }^{6}$ In other words, differentiation of MCKD2 and FJHN apparently is not supported by a different phenotype and appears conceptually artful. For this reason, other investigators $^{12,49,53}$ have proposed the term MCKD2/ FJHN complex as an alternative, and we are fully in agreement with this point of view.

\section{Glomerulocystic Kidney Disease}

GCKD is a rare disorder characterized by diffuse glomerular cysts caused by dilatation of Bowman's space. ${ }^{54}$ Tubular cysts in the renal cortex and medulla may coexist, but they are uncommon. GCKD may occur as a sporadic disorder in association with other renal diseases, such as glomerulonephritis, ${ }^{55}$ systemic lupus erythematosus, ${ }^{56}$ and hemolytic uremic syndrome. ${ }^{57}$ Alternatively, GCKD is inherited as part of a wide spectrum of malformations, as in oral-facial-digital syndrome,${ }^{58}$ or associated with maturity-onset diabetes (MODY5). In the latter case, mutations of the hepatocyte nuclear fac- tor-1 $\beta$ gene $(H N F-1 \beta)$ have been reported. ${ }^{59}$ Interestingly, a mutation in $H N F-1 \beta$ recently also was found in 1 family with atypical FJHN associated with renal cysts, urogenital malformations, and diabetes. ${ }^{60}$ Unfortunately, the presence of cysts affecting glomeruli was not excluded in all patients in this kindred because glomerular cysts cannot be differentiated readily from those localized in tubuli by means of ultrasonography; a renal biopsy is required for a differential diagnosis. Finally, another family with autosomal dominant GCKD has been described. ${ }^{54}$

A missense mutation $(\mathrm{C} 315 \mathrm{R})$ in the $U M O D$ gene recently was reported in a family segregating autosomal dominant GCKD. ${ }^{10,61}$ The cysteine to arginine change maps to cbEGF domain $\mathrm{IV},{ }^{10}$ where other $U M O D$ mutations have been found in patients with MCKD2/FJHN. It seems worth reporting here that all members of the unique family with GCKD and UMOD mutations showed severe impairment of urine-concentration capability and hyperuricemia and probably differ from those carrying MODY5associated $H N F-1 \beta$ mutations. The phenotype of the index family we described ${ }^{10}$ directly shares some features with MCKD2 and FJHN, and it is difficult to establish how unique these features are among GCKD families. Data for urineconcentration capability in the previously described pedigrees with dominant GCKD are scanty. In the only family for which a detailed analysis of urinary parameters is available, ${ }^{62}$ urine concentration after overnight water deprivation was altered, and few patients had hyperuricemia. Moreover, coexistence of glomerular and medullary cysts has been described in different reports, ${ }^{63,64}$ and additional studies addressing this clinical issue in families with dominant GCKD are warranted.

A few pathogenic aspects relative to GCKD in experimental models and humans reinforce the original finding of a role of uromodulin in GCKD. One point is that glomerular cysts may be generated experimentally by ureteric obstruction in fetal sheep ${ }^{65}$ therefore suggesting that early mechanical forces may inhibit full development of the glomerular tuft. Conversely, dense aggregates of uromodulin in tubular cells protruding in the lumen have been described in patients with GCKD, mimicking, in some way, an obstructive condition. Moreover, histochemical studies 
showed an abnormal presence of uromodulin within glomerular cysts. ${ }^{66,67}$ Therefore, these data suggest that a possible mechanism for glomerular cysts could be partial tubular obstruction and consequent reflux of urine (and uromodulin) in Bowman's space.

In conclusion, $H N F-1 \beta$ and $U M O D$ appear to be the relevant genes in GCKD. This finding may underscore a casual relationship between the 2, but a pathogenic link cannot be ruled out. Recent molecular studies indicate that a specific $H N F-1 \beta$ element is present in cis in the UMOD promoter and that uromodulin (together with genes involved in murine polycystic kidneys) is downregulated in mice lacking $H N F-1 \beta^{-} \digamma$ for targeted engineering. ${ }^{68}$

\section{THE LESSON FROM MICE WITH GENETIC ABLATION OF Umod}

Results of targeted genetic ablation of Umod in mice recently were published independently by 2 different groups. ${ }^{30,31}$ As expected, Umod deficiency predisposed mice to bladder colonization by type- 1 fimbrated $E$ coli. This is the first demonstration of a role of the protein in innate urinary defense in vivo. Unfortunately, data for urine-concentrating capability and other biochemical parameters, such as acid uric levels in knockout mice, have not been reported, preventing a comparison with patients with MCKD2/ FJHN/GCKD. Surprisingly, results from renal histological examination, obtained at 2 to 3 months of age, do not show the typical features of tubulointerstitial fibrosis and cysts. In agreement with this finding, Bates et $\mathrm{al}^{31}$ reported that no cysts or fibrosis were present in their mice with Umod ablation, even after 24 months. Together, data on $\operatorname{Umod}^{-} \Gamma$ mice conclusively document the absence of any morphological defects observed in humans with UMOD mutations. Therefore, it seems reasonable to hypothesize that renal histological changes observed in humans are more directly the result of an alteration in uromodulin processing and storage within tubule cells than the consequence of the protein absence. Data for delayed cell maturation of mutated uromodulin, ${ }^{10}$ discussed in the following section, reinforce this hypothesis.

\section{FINE MECHANISMS RELATED TO DELAYED CELL MATURATION AND STORAGE}

Immunohistological analysis of the kidney in patients with $U M O D$ mutations turned out to be crucial to outline basic features of uromodulin renal expression in these patients, stimulating additional in vitro experiments in renal cells. Looking at both MCKD2 and GCKD renal biopsy specimens, uromodulin was found in patchy deposits in the cytoplasm along the TAL of Henle. This pattern of uromodulin deposition, shown in Fig 1, was described first by Rampoldi et al ${ }^{10}$ and Dahan et al. ${ }^{9}$ These deposits probably coincide with the fibrillar material in the endoplasmic reticulum (ER) shown by electron microscopy. However, the immunogold assay was not available; hence, there is no conclusive evidence that the fibrillar material is uromodulin.

Because mutations affecting disulfide bonds, as well as those reducing calcium-binding affinity, most likely cause misfolding of the global protein structure, it was hypothesized that these changes could lead to delayed maturation and hence intracellular accumulation in tubular cells of patients carrying $U M O D$ mutations. Experiments with renal cells in vitro support this possibility. ${ }^{10}$ The effect of 4 different UMOD missense mutations identified in patients with MCKD2/FJHN and GCKD and affecting cysteine residues 148, 150, 315, and 317 was analyzed by means of transient transfection of wildtype and mutant constructs in the cell lines HEK293 and HeLa, which do not normally express uromodulin. The amount of protein exposed on the plasma membrane was dramatically reduced in mutant-transfected cells. Colocalization experiments showed that delay of mutant export to the plasma membrane was determined by longer retention in the ER. At short times after transfection, most wild-type uromodulin localized to the Golgi apparatus, whereas mutant isoforms mainly localized in the ER, with little, if any, signal in the Golgi. Wild-type uromodulin behaves in denaturing conditions like mutated isoforms, confirming the central role of proper protein folding in uromodulin maturation steps. Accumulation of mutant uromodulin in the ER is of particular interest because this is the site for conformation stabilization of any protein by disulfide isomerases that should be hampered in 



Fig 1. Immunohistochemical examination with antiuromodulin antibodies of kidney samples from patients with MCKD2. (A) Kidney sections $0.3-\mu \mathrm{m}$ thick were incubated first with monoclonal antiuromodulin antibodies (1032A clone; Cedarlane, Hornby, Ontario, Canada), followed by incubation with goat antimouse immunoglobulin G linked to biotin. Staining was with developed streptavidin peroxidase and diaminobenzidin. Intracellular aggregates of mutant uromodulin are evident in both cases. (Original magnification $\times 100$.) (B) Transmission electron microscopic examination of the same patient as $A$ shows accumulating dense material, mostly in the ER. (Original magnification $\times 5,700$.)

the case of uromodulin-mutated isoforms. The ER has a resident machinery based on chaperons that assists protein folding and ensures that only properly folded proteins move along the secretory pathway. ${ }^{69}$ Accordingly, unfolded proteins are bound to chaperons, retained in the ER, ${ }^{70}$ and ultimately degraded in the cytosol. The mechanism of degradation appears to be complex and involves ubiquitin, ER-ubiquitin-conjugating enzymes, and the proteosome complex. ${ }^{71,72}$

Failure of correct folding and sorting triggers the so-called ER stress response, which involves
2 different pathways known as unfolded protein response and ER overload response, the latter involving nuclear factor- $\kappa \mathrm{B}$ induction as mediator of an inflammatory response. Further investigation will be needed to assess whether cell stress by ER accumulation of unfolded mutant uromodulin may trigger the unfolded protein response and ER overload response and, eventually, programmed cell death. ${ }^{73}$ Analysis of urinary uromodulin content is in full agreement with the idea of accumulation of unfolded uromodulin in tubular cells. In the report by Rampoldi et al, ${ }^{10}$ a marked decrease in urinary uromodulin levels consistent with the immunohistochemistry observation of uromodulin patch deposits in tubular cells was shown in 1 MCKD2 family. Urinary uromodulin content in patients with FJHN was investigated thoroughly by Dahan et al, ${ }^{9}$ who showed a consistent decrease in patients with $U M O D$ mutations compared with healthy subjects and patients with chronic renal failure from other causes. Chemical and mass spectrometry analysis showed the presence of only wild-type uromodulin in urine from patients with FJHN. ${ }^{9}$ Together, these observations suggest that mutated uromodulin accumulates in tubular cells owing to misfolding, whereas the wild-type protein is processed normally and excreted in urine. Nevertheless, because reduced urinary excretion of uromodulin has been reported in several nephropathies, it is not clear whether the reduction observed in patients with MCKD2/FJHN may be secondary to distal tubule damage. ${ }^{74,75}$

\section{PATHOLOGICAL EXAMINATION AND MECHANISMS OF GROSS SYMPTOMS}

Diffuse tubulointerstitial fibrosis is a constant pathological finding in all patients with MCKD2/ FJHN undergoing renal biopsy. ${ }^{9,10}$ A concomitant feature is the presence of tubule dilatations, reaching, in some cases, the dignity of tubular cysts. Tubule basement membrane appears duplicated in some segments; however, this feature also is present in other nephropathies with an advanced stage of renal involvement. ${ }^{1}$ As discussed previously, severe impairment of urinaryconcentrating capability is a major and almost constant clinical symptom in all patients with $\mathrm{MCKD} / \mathrm{FJHN}$, whereas hyperuricemia is not constant and often is associated with renal cysts. ${ }^{6-13}$ 


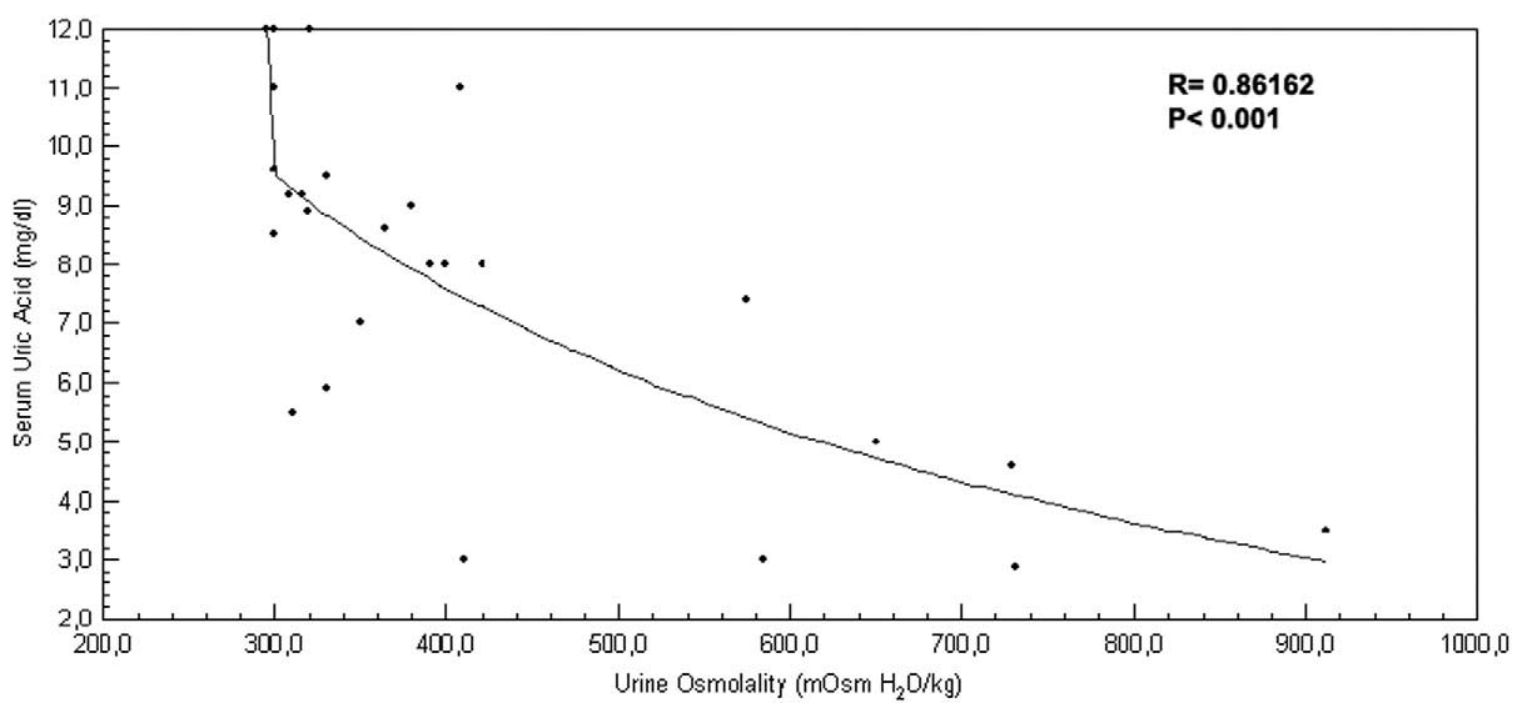

Fig 2. Correlation between serum uric acid level and urine osmolality in 26 patients with MCKD2 and proven mutations of UMOD. ${ }^{10}$ For this correlation, only affected patients from 3 families with MCKD2 were enrolled. Morning urine osmolality values were plotted against serum uric levels. The strong correlation between the defect in urine-concentrating capability and serum uric acid level suggests a mechanism linked with fluid deprivation in patients with hyperuricemia. The best fit was given by the following curve: $Y=a+b * \log (x) / X^{\wedge} 2+c * \exp (-x)$ with $R^{2}=$ $0.74275(P<0.001)$.

It is of note that some pathological and biochemical features, such as tubulointerstitial fibrosis, formation of medullary and cortical cysts (in patients with MCKD2 and GCKD, respectively), and hyperuricemia remain difficult to explain on the basis of the protein putative function(s).

\section{Defect in the Urine-Concentrating Process}

Uromodulin expression is exclusive of epithelial cells of the TAL, ${ }^{15,16}$ which are nephron segments characterized by high electrolyte/water permeability. ${ }^{18}$ For this reason, it was proposed that uromodulin has a role in salt transport and water impermeability at this level, a process crucial for urine concentration. Personalized data for morning urine osmolality are available for 32 patients, 7 patients described by Bleyer et $\mathrm{al}^{13}$ and 25 patients from our cohort (G.M. Ghiggeri, personal observation). All except 2 patients had values less than $800 \mathrm{mOsm} / \mathrm{L}$, and values lower than $600 \mathrm{mOsm} / \mathrm{L}$ were present in 26 patients (Fig 2). Therefore, low urine osmolality is an almost constant finding in patients with $U M O D$ mutations. Water reabsorption by the tubule is regulated by a complex transmembrane system that includes aquaporin and ion channels (for review, see Agre and Kozona ${ }^{76}$ ), and it currently is unknown how uromodulin could interact with them. Experimental data support the hypothesis of involvement of uromodulin in salt uptake in the TAL because studies of rats fed different dietary salt loads showed that uromodulin messenger RNA and protein levels were increased with a high-salt diet. The failure of uromodulin to properly form the water barrier in the TAL could explain the marked defect in the urineconcentrating process that determines low urine osmolality in patients affected by these disorders. ${ }^{77,78}$ Water income in the TAL would reduce sodium chloride reabsorption by the TAL Na-K$2 \mathrm{Cl}$ cotransporter, responsible for $25 \%$ of the total sodium renal uptake. This would affect not only urine-concentrating capability, but also maintenance of the countercurrent gradient.

\section{Tubulointerstitial Fibrosis}

Tubulointerstitial fibrosis is constituted mainly by deposition of type I and III interstitial collagens. Interstitial collagen deposition represents a common mechanism acting in many, if not all, renal diseases evolving to chronic renal failure. It should arise from a complex series of events culminating in renal infiltration by nonresident macrophages, cytokine production, and stimula- 
tion of collagen synthesis by tubular epithelial cells and fibroblasts. Although uromodulin may be implicated in several steps of the fibrotic cascade, any conclusion on the mechanism(s) implicated in renal fibrosis in patients with MCKD2/FJHN remains highly speculative. A direct relationship between uromodulin and collagen metabolism cannot be ruled out because no study addressing this aspect has been published to date, and this represents an interesting area for future research. What we can reasonably exclude is a relationship with the antibacterial functions of uromodulin ${ }^{28}$ because the frequency of episodes of urinary tract infection is not increased in patients with MCKD2/FJHN, and, probably, wildtype uromodulin secretion overcomes the antibacterial requests in these patients. Moreover, lack of renal fibrosis in $\mathrm{Umod}^{-} \Gamma$ mice at 24 months of age is strongly against this possibility. ${ }^{31}$ Conversely, several observations suggested that uromodulin may have direct inflammatory properties because it modulates cytokine secretion by nonresident monocytes ${ }^{79}$ and granulocytes ${ }^{80}$; therefore, upregulation by mutated isoforms should be excluded.

Finally, tubulointerstitial nephritis in the TAL can be induced in rabbits and rats after administration of uromodulin. ${ }^{81,82}$ Clinical studies showed uromodulin deposits in tubular interstitium in several human conditions characterized by tubulointerstitial fibrosis, including MCKD. ${ }^{66,67,81}$ Uromodulin is a powerful immunogen, and antiuromodulin antibodies have been localized in renal interstitium after uromodulin administration to rats. ${ }^{82,83}$ Healthy humans do not produce antiuromodulin antibodies for segregation of the protein at the luminal face of tubular cells. However, loss of cell polarity or altered cell processing, such as accumulation in the ER, could interfere with proteosome degradation $^{84}$ of misfolded mutant protein, determining basal localization. The only 2 studies showing immunopathologic data for kidneys of patients with proven $U M O D$ mutations do not show uromodulin interstitial deposits, ${ }^{9,10}$ ruling out this mechanism. Alternatively, renal fibrosis could be the consequence of inflammatory and immune responses mediated by upregulation of nuclear factor- $\kappa \mathrm{B}$, which is a key step in the ER overload response pathway. ${ }^{85}$

\section{Cystogenesis}

Despite the name of the disease incorporating the term "cystic," medullary cysts are not a common finding in patients with MCKD2. ${ }^{86}$ Medullary cysts derive from enlargements of collecting tubules and remain connected to the nephron of origin. In patients with GCKD, cyst dilatations occur prevalently at the Bowman's space level and may be extended to some tubules. This appears to be different from patients with PKD, for whom cysts arise in every tubule segment and rapidly close off from the nephron of origin. ${ }^{87}$ Therefore, cystogenesis in patients with MCKD2 and GCKD should follow different mechanisms. The small cysts described in patients with MCKD2 could arise from tubule dilatation, possibly caused by water income, which would be expected in the absence of a uromodulin water barrier in the TAL. However, the reason for the scattered involvement and wide interfamilial and intrafamilial variability remains unknown. Based on our current lack of knowledge on the topics, hypothetical effects of modifier genes or a 2-hit mechanism having a role in selected segments of the same kidney cannot be excluded. Conversely, glomerular cysts are a constant feature in affected members of a family with GCKD with UMOD mutations. ${ }^{10}$ Studies that appeared in the mid-1970s showed an abnormal presence of uromodulin within glomerular cysts ${ }^{66}$ in patients who obviously were not characterized on molecular grounds. In our hands, immunohistologic examination did not show uromodulin in enlarged Bowman's space. Despite these inconsistencies, we hypothesized a mechanism of dilatation of Bowman's space linked to tubular obstruction that would determine urine reflux and in some way mimic an obstructive condition. As discussed, the experimental generation of glomerular cysts by ureteric ligation in fetal sheep ${ }^{65}$ reinforces our hypothesis.

\section{Hyperuricemia}

Hyperuricemia is a common feature in patients with MCKD2/FJHN, involving approximately $65 \%$ to $75 \%$ of patients without relevant interfamilial and intrafamilial differences. It is caused by an increment in tubular reabsorption of urates; this defect is unique among any other inherited conditions. ${ }^{1,39,87}$ 
A point of interest is to look at clinical parameters that correlate with hyperuricemia. We found an inverse correlation between urine osmolality and uric acid levels in 26 carriers of $U M O D$ mutations (Fig 2), suggesting an implication of plasma volume in hyperuricemia. Bleyer et $\mathrm{al}^{13}$ reported fractional excretion of uric acid greater than $5 \%$ in 18 of 41 affected patients, with an inverse correlation with creatinine clearance, suggesting an effect of renal function on this parameter. The net balance of urate excretion is the result of reabsorption, secretion, and postsecretory reabsorption. In human kidneys, the first 2 phases are confined to the proximal tubule, where 2 specific transporters, ${ }^{88}$ ie, human urate transporter and human urate transporter/channel, have been characterized. ${ }^{89,90}$

Much less is known about the secretion and postsecretion of urate in nephron segments. Available data for uromodulin localization in patients with normal and pathological conditions ${ }^{18}$ argue against a direct implication of uromodulin in urate reabsorption. Based on the strong correlation between hyperuricemia and urine osmolality (which gives an indirect estimate of water deprivation), we hypothesize an indirect mechanism linked to volume contraction and maintenance of the countercurrent gradient by uromodulin that has already been discussed for water reabsorption. The association between reduced sodium reabsorption in the TAL, ie, activity of the Na-K$2 \mathrm{Cl}$ cotransporter, and hyperuricemia has been reported as a side effect of long-term administration of loop diuretics ${ }^{91}$ and in 50\% of patients with Bartter's syndrome, a variant of which is associated with mutations of the gene encoding the Na-K-2Cl cotransporter. ${ }^{92}$ The decreased sodium uptake in the TAL would be compensated for by enhanced sodium reabsorption in the proximal tubule that would increase the activity of the human urate transporter. ${ }^{91}$ Additional studies are needed to show this hypothesis.

\section{CONCLUSIONS: UMOD-RELATED CONDITIONS AS A MODEL OF RENAL STORAGE DISEASE}

It appears from the review of the recent literature on $U M O D$ mutations that they are associated with a variable panel of symptoms that, in the past, have been associated with specific pathological states. Most frequently, mutations involve cysteine residues in 1 of the predicted
cbEGF domains, with a cluster of mutations at exons 4 and 5. This occurs independently in patients with MCKD2 and FJHN, suggesting that the artful distinction between the 2 entities should not exist. Cell biology experiments showed that misfolded uromodulin has delayed maturation and accumulates in the ER. Lack of cellular uromodulin function impairs tubular function, particularly water reabsorption, determining water depletion and hyperuricemia. The presence of mutant uromodulin aggregates could trigger a stress response in the cell that might be a key step in the pathogenesis of these disorders. For this reason, we propose the definition of uromodulin storage disease for the mentioned conditions with proven $U M O D$ mutations.

\section{REFERENCES}

1. Hildebrandt F: Nephronophthisis-medullary cystic kidney disease, in Avner ED, Harmon WE, Niaudet P, and 132 contributors (eds): Pediatric Nephrology, 5th Edition. Philadelphia, PA, Lippincott Williams and Wilkins, 2004, pp 665-673

2. Hildebrandt F, Otto E, Rensing C, et al: A novel gene encoding an SH3 domain protein is mutated in nephronophthisis type 1. Nat Genet 17:149-153, 1997

3. Otto E, Hoefele J, Ruf R, et al: A gene mutated in nephronophthisis and retinitis pigmentosa encodes a novel protein, nephroretinin, conserved in evolution. Am J Hum Genet 71:1161-1167, 2002

4. Otto EA, Schermer B, Obara T, et al: Mutations in INVS encoding inversin cause nephronophthisis type 2, linking renal cystic disease to the function of primary cilia and left-right axis determination. Nat Genet 34:413-420, 2003

5. Olbrich H, Fliegauf M, Hoefele J, et al: Mutations in a novel gene, NPHP3, cause adolescent nephronophthisis, tapeto-retinal degeneration and hepatic fibrosis. Nat Genet 34:455-459, 2003

6. Hart TC, Gorry MC, Hart PS, et al: Mutations of the UMOD gene are responsible for medullary cystic kidney disease 2 and familial juvenile hyperuricaemic nephropathy. J Med Genet 39:882-892, 2002

7. Wolf MT, Mucha BE, Attanasio M, et al: Mutations of the uromodulin gene in MCKD type 2 patients cluster in exon 4, which encodes three EGF-like domains. Kidney Int 64:1580-1587, 2003

8. Turner JJ, Stacey JM, Harding B, et al: Uromodulin mutations cause familial juvenile hyperuricemic nephropathy. J Clin Endocrinol Metab 88:1398-1401, 2003

9. Dahan K, Devuyst O, Smaers M, et al: A cluster of mutations in the UMOD gene causes familial juvenile hyperuricemic nephropathy with abnormal expression of uromodulin. J Am Soc Nephrol 14:2883-2893, 2003

10. Rampoldi L, Caridi G, Santon D, et al: Allelism of MCKD, FJHN and GCKD caused by impairment of uro- 
modulin export dynamics. Hum Mol Genet 12:3369-3384, 2003

11. Kudo E, Kamatani N, Tezuka O, et al: Familial juvenile hyperuricemic nephropathy: Detection of mutations in the uromodulin gene in five Japanese families. Kidney Int 65:1589-1597, 2004

12. Bleyer AJ, Trachtman H, Sandhu J, Gorry MC, Hart TC: Renal manifestations of a mutation in the uromodulin (Tamm-Horsfall protein) gene. Am J Kidney Dis 42:E20E26, 2003

13. Bleyer AJ, Woodard AS, Shihabi Z, et al: Clinical characterization of a family with a mutation in the uromodulin (Tamm-Horsfall glycoprotein) gene. Kidney Int 64:3642, 2003

14. Rezende-Lima W, Parreira KS, Garcìa-Gonzàlez M, Riveria E, Banet JF, Lens XM: Homozygosity for uromodulin disorders: FJHN and MCKD-type 2. Kidney Int 66:558563,2004

15. Bachmann S, Metzger R, Bunnemann B: TammHorsfall protein-mRNA synthesis is localized to the thick ascending limb of Henle's loop in rat kidney. Histochemistry 94:517-523, 1990

16. Gokhale JA, Glenton PA, Khan SR: Characterization of Tamm-Horsfall protein in a rat nephrolithiasis model. J Urol 166:1492-1497, 2001

17. Heptinstall RH: Interstitial nephritis. A brief review. Am J Pathol 83:213-236, 1976

18. Serafini-Cessi F, Malagolini N, Cavallone D: TammHorsfall glycoprotein: Biology and clinical relevance. Am J Kidney Dis 42:658-676, 2003

19. Pennica D, Kohr WJ, Kuang WJ, et al: Identification of human uromodulin as the Tamm-Horsfall urinary glycoprotein. Science 236:83-88, 1987

20. Hession C, Decker JM, Sherblom AP, et al: Uromodulin (Tamm-Horsfall glycoprotein): A renal ligand for lymphokines. Science 237:1479-1484, 1987

21. Fukuoka S, Freedman SD, Yu H, Sukhatme VP, Scheele GA: GP-2/THP gene family encodes self-binding glycosylphosphatidylinositol-anchored proteins in apical secretory compartments of pancreas and kidney. Proc Natl Acad Sci U S A 89:1189-1193, 1992

22. Prasadan K, Bates J, Badgett A, et al: Nucleotide sequence and peptide motifs of mouse uromodulin (TammHorsfall protein)-The most abundant protein in mammalian urine. Biochim Biophys Acta 1260:328-332, 1995

23. Yu H, Papa F, Sukhatme VP: Bovine and rodent Tamm-Horsfall protein (THP) genes: Cloning, structural analysis, and promoter identification. Gene Expr 4:63-75, 1994

24. Jovine L, Qi H, Williams Z, Litscher E, Wassarman PM: The ZP domain is a conserved module for polymerization of extracellular proteins. Nat Cell Biol 4:457-461, 2002

25. Cox ML, Quignon P, Galibert F, Lees GE, Murphy KE: Sequencing and radiation hybrid mapping of canine uromodulin. DNA Seq 14:61-69, 2003

26. Orskov I, Ferencz A, Orskov F: Tamm-Horsfall protein or uromucoid is the normal urinary slime that traps type 1 fimbriated Escherichia coli. Lancet 1:887, 1980

27. Parkkinen J, Virkola R, Korhonen TK: Identification of factors in human urine that inhibit the binding of Escherichia coli adhesins. Infect Immun 56:2623-2630, 1988
28. Pak J, Pu Y, Zhang ZT, Hasty DL, Wu XR: TammHorsfall protein binds to type 1 fimbriated Escherichia coli and prevents $E$ coli from binding to uroplakin $\mathrm{Ia}$ and $\mathrm{Ib}$ receptors. J Biol Chem 276:9924-9930, 2001

29. Wu XR, Sun TT, Medina JJ: In vitro binding of type 1-fimbriated Escherichia coli to uroplakins Ia and Ib: Relation to urinary tract infections. Proc Natl Acad Sci U S A 93:9630-9635, 1996

30. Mo L, Zhu XH, Huang HY, Shapiro E, Hasty DL, Wu XR: Ablation of the Tamm-Horsfall protein gene increases susceptibility of mice to bladder colonization by type 1-fimbriated Escherichia coli. Am J Physiol Renal Physiol 286: F795-F802, 2004

31. Bates JM, Raffi HM, Prasadan K, et al: TammHorsfall protein knockout mice are more prone to urinary tract infection: Rapid communication. Kidney Int 65:791797, 2004

32. McQueen EG: Composition of urinary casts. Lancet 1:397-398, 1966

33. Wangsiripaisan A, Gengaro PE, Edelstein CL, Schrier RW: Role of polymeric Tamm-Horsfall protein in cast formation: Oligosaccharide and tubular fluid ions. Kidney Int 59:932-940, 2001

34. Sanders PW, Booker BB, Bishop JB, Cheung HC: Mechanisms of intranephronal proteinaceous cast formation by low molecular weight proteins. J Clin Invest 85:570-576, 1990

35. Huang ZQ, Sanders PW: Biochemical interaction between Tamm-Horsfall glycoprotein and Ig light chains in the pathogenesis of cast nephropathy. Lab Invest 73:810817,1995

36. Coe FL, Parks JH, Asplin JR: The pathogenesis and treatment of kidney stones. N Engl J Med 327:1141-1152, 1992

37. Miyake O, Yoshioka T, Yoshimura K, et al: Expression of Tamm-Horsfall protein in stone-forming rat models. Br J Urol 81:14-19, 1998

38. Worcester EM: Urinary calcium oxalate crystal growth inhibitors. J Am Soc Nephrol 5:S46-S53, 1994 (suppl 1)

39. Hildebrandt F, Otto E: Molecular genetics of nephronophthisis and medullary cystic kidney disease. J Am Soc Nephrol 11:1753-1761, 2000

40. Ong AC, Wheatley DN: Polycystic kidney diseaseThe ciliary connection. Lancet 361:774-776, 2003

41. Taulman PD, Haycraft CJ, Balkovetz DF, Yoder BK: Polaris, a protein involved in left-right axis patterning, localizes to basal bodies and cilia. Mol Biol Cell 12:589599,2001

42. Hou X, Mrug M, Yoder BK, et al: Cystin, a novel cilia-associated protein, is disrupted in the cpk mouse model of polycystic kidney disease. J Clin Invest 109:533-540, 2002

43. Yoder BK, Hou X, Guay-Woodford LM: The polycystic kidney disease proteins, polycystin-1, polycystin-2, polaris, and cystin, are co-localized in renal cilia. J Am Soc Nephrol 13:2508-2516, 2002

44. Nauli SM, Alenghat FJ, Luo Y, et al: Polycystins 1 and 2 mediate mechanosensation in the primary cilium of kidney cells. Nat Genet 33:129-137, 2003

45. Christodoulou K, Tsingis M, Stavrou C, et al: Chromosome 1 localization of a gene for autosomal dominant 
medullary cystic kidney disease. Hum Mol Genet 7:905-911, 1998

46. Scolari F, Puzzer D, Amoroso A, et al: Identification of a new locus for medullary cystic disease, on chromosome 16p12. Am J Hum Genet 64:1655-1660, 1999

47. Stiburkova B, Majewski J, Sebesta I, Zhang W, Ott J, Kmoch S: Familial juvenile hyperuricemic nephropathy: Localization of the gene on chromosome $16 \mathrm{p} 11.2$ and evidence for genetic heterogeneity. Am J Hum Genet 66:19891994, 2000

48. Kamatani N, Moritani M, Yamanaka H, Takeuchi F, Hosoya T, Itakura M: Localization of a gene for familial juvenile hyperuricemic nephropathy causing underexcretiontype gout to $16 \mathrm{p} 12$ by genome-wide linkage analysis of a large family. Arthritis Rheum 43:925-929, 2000

49. Dahan K, Fuchshuber A, Adamis S, et al: Familial juvenile hyperuricemic nephropathy and autosomal dominant medullary cystic kidney disease type 2: Two facets of the same disease? J Am Soc Nephrol 12:2348-2357, 2001

50. Stiburkova B, Majewski J, Hodanova K, et al: Familial juvenile hyperuricaemic nephropathy (FJHN): Linkage analysis in 15 families, physical and transcriptional characterisation of the FJHN critical region on chromosome 16p11.2 and the analysis of seven candidate genes. Eur J Hum Genet 11:145-154, 2003

51. Kroiss S, Huck K, Berthold S, et al: Evidence of further genetic heterogeneity in autosomal dominant medullary cystic kidney disease. Nephrol Dial Transplant 15:818821,2000

52. Auranen M, Ala-Mello S, Turunen JA, Jarvela I: Further evidence for linkage of autosomal-dominant medullary cystic kidney disease on chromosome 1q21. Kidney Int 60:1225-1232, 2001

53. Kotanko P, Gebetsroither E, Skrabal F: Familial juvenile hyperuricaemic nephropathy in a Caucasian family associated with inborn malformations. Nephrol Dial Transplant 17:1333-1335, 2002

54. Sharp CK, Bergman SM, Stockwin JM, Robbin ML, Galliani C, Guay-Woodford LM: Dominantly transmitted glomerulocystic kidney disease: A distinct genetic entity. J Am Soc Nephrol 8:77-84, 1997

55. Oh Y, Onoyama K, Kobayashi K, et al: Glomerulocystic kidneys. Report of an adult case. Nephron 43:299-302, 1986

56. Carson RW, Bedi D, Cavallo T, DuBose TD Jr: Familial adult glomerulocystic kidney disease. Am J Kidney Dis 9:154-165, 1987

57. Emma F, Muda AO, Rinaldi S, Boldrini R, Bosman C, Rizzoni G: Acquired glomerulocystic kidney disease following hemolytic uremic syndrome. Pediatr Nephrol 16: 557-560, 2001

58. Feather SA, Winyard PJ, Dodd S, Woolf AS: Oralfacial-digital syndrome type 1 is another dominant polycystic kidney disease: Clinical, radiological and histopathological features of a new kindred. Nephrol Dial Transplant 12:1354-1361, 1997

59. Bingham C, Bulman MP, Ellard S, et al: Mutations in the hepatocyte nuclear factor-1beta gene are associated with familial hypoplastic glomerulocystic kidney disease. Am J Hum Genet 68:219-224, 2001
60. Bingham C, Ellard S, van't Hoff WG, et al: Atypical familial juvenile hyperuricemic nephropathy associated with a hepatocyte nuclear factor-1beta gene mutation. Kidney Int 63:1645-1651, 2003

61. Gusmano R, Caridi G, Marini M, et al: Glomerulocystic kidney disease in a family. Nephrol Dial Transplant 17:813-818, 2002

62. Melnick SC, Brewer DB, Oldham JS: Cortical microcystic disease of the kidney with dominant inheritance: A previously undescribed syndrome. J Clin Pathol 37:494-499, 1984

63. Woronik V, Saldanha LB, Sabbaga E, Marcondes M: Glomerulocystic disease and medullary cystic disease: An unusual association. Clin Nephrol 37:158, 1992

64. Kobayashi Y, Hiki Y, Shigematsu H, Tateno S, Mori $\mathrm{K}$ : Renal retinal dysplasia with diffuse glomerular cysts. Nephron 39:201-205, 1985

65. Attar R, Quinn F, Winyard PJ, et al: Short-term urinary flow impairment deregulates PAX2 and PCNA expression and cell survival in fetal sheep kidneys. Am J Pathol 152:1225-1235, 1998

66. Resnick JS, Sisson S, Vernier RL: Tamm-Horsfall protein. Abnormal localization in renal disease. Lab Invest 38:550-555, 1978

67. Chambers R, Groufsky A, Hunt JS, Lynn KL, McGiven AR: Relationship of abnormal Tamm-Horsfall glycoprotein localization to renal morphology and function. Clin Nephrol 26:21-26, 1986

68. Gresh L, Fischer E, Reimann A, et al: A transcriptional network in polycystic kidney disease. EMBO J 23: 1657-1668, 2004

69. Ellgaard L, Molinari M, Helenius A: Setting the standards: Quality control in the secretory pathway. Science 286:1882-1888, 1999

70. Hartl FU: Molecular chaperones in cellular protein folding. Nature 381:571-579, 1996

71. Ciechanover A, Schwartz AL: The ubiquitin-proteasome pathway: The complexity and myriad functions of proteins death. Proc Natl Acad Sci U S A 95:2727-2730, 1998

72. Hershko A, Ciechanover A, Varshavsky A: Basic medical research award. The ubiquitin system. Nat Med 6:1073-1081, 2000

73. Wang XZ, Harding HP, Zhang Y, Jolicoeur EM, Kuroda M, Ron D: Cloning of mammalian Ire1 reveals diversity in the ER stress responses. EMBO J 17:5708-5717, 1998

74. Schroter J, Timmermans G, Seyberth HW, Greven J, Bachmann S: Marked reduction of Tamm-Horsfall protein synthesis in hyperprostaglandin E-syndrome. Kidney Int 44:401-410, 1993

75. Torffvit O, Jorgensen PE, Kamper AL, et al: Urinary excretion of Tamm-Horsfall protein and epidermal growth factor in chronic nephropathy. Nephron 79:167-172, 1998

76. Agre P, Kozono D: Aquaporin water channels: Molecular mechanisms for human diseases. FEBS Lett 555:7278, 2003

77. Ying WZ, Sanders PW: Dietary salt regulates expression of Tamm-Horsfall glycoprotein in rats. Kidney Int 54:1150-1156, 1998 
78. Mattey M, Naftalin L: Mechanoelectrical transduction, ion movement and water stasis in uromodulin. Experientia 48:975-980, 1992

79. Su SJ, Chang KL, Lin TM, Huang YH, Yeh TM: Uromodulin and Tamm-Horsfall protein induce human monocytes to secrete TNF and express tissue factor. J Immunol 158:3449-3456, 1997

80. Thomas DB, Davies M, Peters JR, Williams JD: Tamm Horsfall protein binds to a single class of carbohydrate specific receptors on human neutrophils. Kidney Int 44:423-429, 1993

81. Zager RA, Cotran RS, Hoyer JR: Pathologic localization of Tamm-Horsfall protein in interstitial deposits in renal disease. Lab Invest 38:52-57, 1978

82. Mayrer AR, Kashgarian M, Ruddle NH, et al: Tubulointerstitial nephritis and immunologic responses to TammHorsfall protein in rabbits challenged with homologous urine or Tamm-Horsfall protein. J Immunol 128:2634-2642, 1982

83. Hoyer JR: Tubulointerstitial immune complex nephritis in rats immunized with Tamm-Horsfall protein. Kidney Int 17:284-292, 1980

84. Kaufman RJ: Orchestrating the unfolded protein response in health and disease. J Clin Invest 110:1389-1398, 2002

85. Pahl HL, Baeuerle PA: A novel signal transduction pathway from the endoplasmic reticulum to the nucleus is mediated by transcription factor NF-kappa B. EMBO J 14:2580-2588, 1995

86. Scolari F, Ghiggeri GM, Casari G, et al: Autosomal dominant medullary cystic disease: A disorder with variable clinical pictures and exclusion of linkage with the NPH1 locus. Nephrol Dial Transplant 13:2536-2546, 1998

87. Wilson PD: Polycystic kidney disease. N Engl J Med 350:151-164, 2004

88. Maesaka JK, Fishbane S: Regulation of renal urate excretion: A critical review. Am J Kidney Dis 32:917-933, 1998

89. Leal-Pinto E, Cohen BE, Lipkowitz MS, Abramson RG: Functional analysis and molecular model of the human urate transporter/channel, hUAT. Am J Physiol Renal Physiol 283:F150-F163, 2002

90. Enomoto A, Kimura H, Chairoungdua A, et al: Molecular identification of a renal urate anion exchanger that regulates blood urate levels. Nature 417:447-452, 2002

91. Brater DC: Benefits and risks of torasemide in congestive heart failure and essential hypertension. Drug Saf 14:104120, 1996

92. Simon DB, Karet FE, Hamdan JM, DiPietro A, Sanjad SA, Lifton RP: Bartter's syndrome, hypokalaemic alkalosis with hypercalciuria, is caused by mutations in the Na-K-2Cl cotransporter NKCC2. Nat Genet 13:183-188, 1996 